\title{
DIAGNOSIS OF FAMILIAL HYPERCHOLESTEROLEMIA IN THE CLINICAL PRACTICE: PERFORMANCE OF THE DUTCH LIPID CLINIC NETWORK SCORE
}

\section{F. Bonaiti ${ }^{1}$, M. Casula ${ }^{1}$, E. Olmastroni ${ }^{1}$, M. Averna ${ }^{2}$, M. Arca ${ }^{3}$, A. L. Catapano ${ }^{1,4}$ on behalf of the LIPIGEN Group}

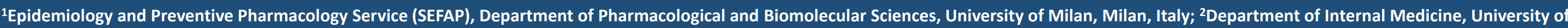
Palermo, Palermo, Italy; ${ }^{3}$ Department of Internal Medicine and Medical Specialties, Sapienza University of Rome, Rome, Italy; ${ }^{4}$ RCCS MultiMedica, Sesto S. Giovanni, Milan, Italy

\section{BACKGROUND}

Familial hypercholesterolemia (FH) is an inherited disorder characterized by high levels of blood cholesterol from birth and premature coronary heart disease (CHD).

Thus, the early identification of $\mathrm{FH}$ patients is crucial to prevent the onset of cardiovascular events. Despite the availability of clinical tools (e.g. Dutch Lipid Clinic Network [DLCN] score) supporting physicians in identifying FH patients, a significant proportion of patients remains without a diagnosis due to lack of information.

\section{RESULTS}

A total of 1377 adults $(48.6 \%$ male; mean age $42.9 \pm 14.2$ years; mean pre-treatment LDL-C level 285.5 \pm 95.0 $\mathrm{mg} / \mathrm{dL}$ ) with geneticallyconfirmed $\mathrm{FH}$ were selected. The DLCN score classified $5.3 \%$ as unlikely (score $0-2$ ), $28.3 \%$ as possible (3-5), $28.5 \%$ as probable (score 6$8)$, and $37.9 \%$ as definite $\mathrm{FH}$ $(>8)$.

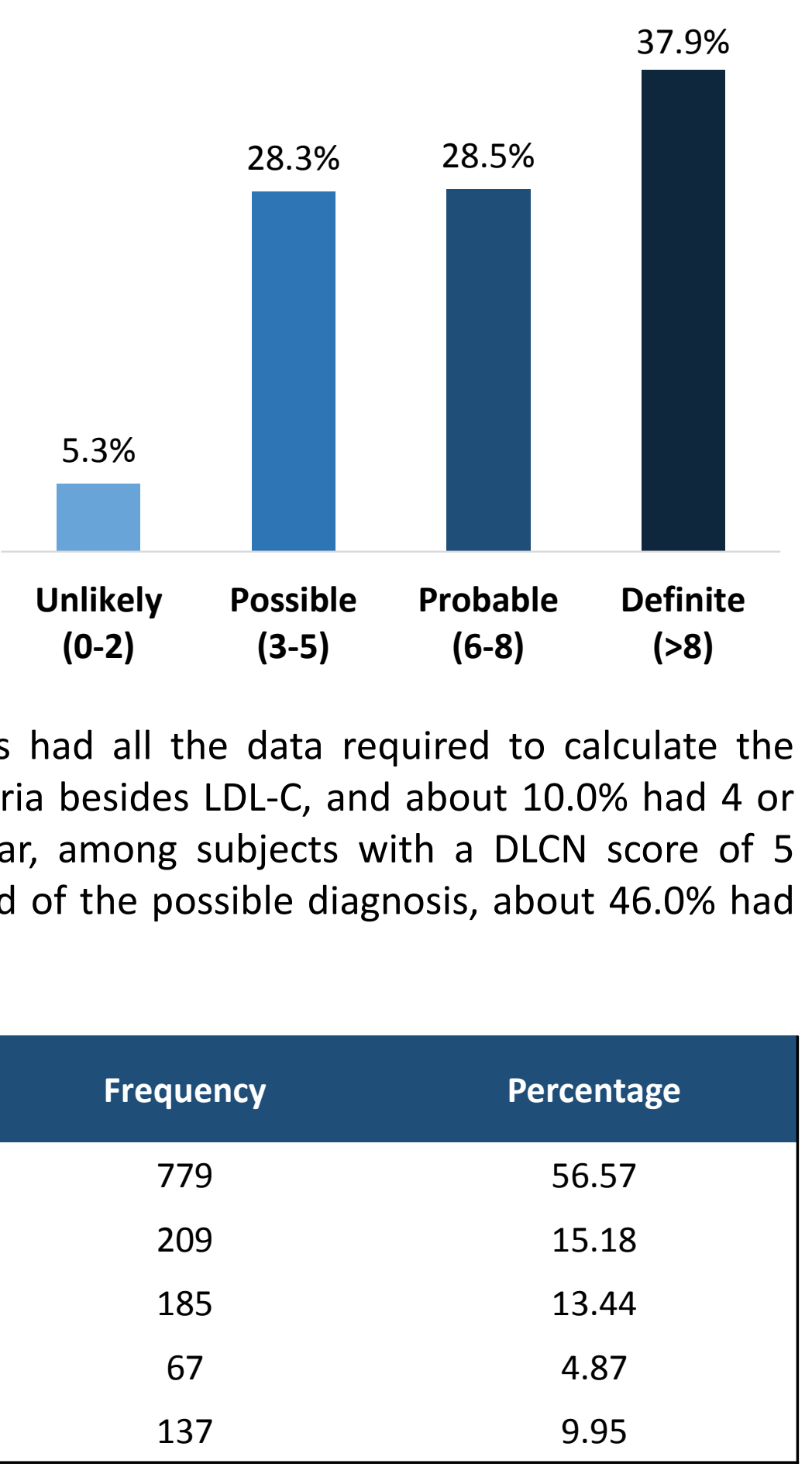

Overall, only $56.6 \%$ of patients had all the data required to calculate the DLCN score through the 8 criteria besides LDL-C, and about $10.0 \%$ had 4 or more missing data. In particular, among subjects with a DLCN score of 5 (9.2\%), just below the threshold of the possible diagnosis, about $46.0 \%$ had at least one missing criteria.

\begin{tabular}{|ccc|}
\hline Number of missing criteria & Frequency & Percentage \\
\hline 0 & 779 & 56.57 \\
1 & 209 & 15.18 \\
2 & 185 & 13.44 \\
3 & 67 & 4.87 \\
$\geq 4$ & 137 & 9.95 \\
\hline
\end{tabular}

Compared with subjects without missing data, the lack of information related to the family clinical history did not modify the rate of patient identified as $\mathrm{FH}$; in contrast, the lack of information concerning the physical signs typical of $\mathrm{FH}$ or the personal history of cardio/cerebrovascular events strongly reduced the percentage of subjects with a probable/definite $\mathrm{FH}$ diagnosis.

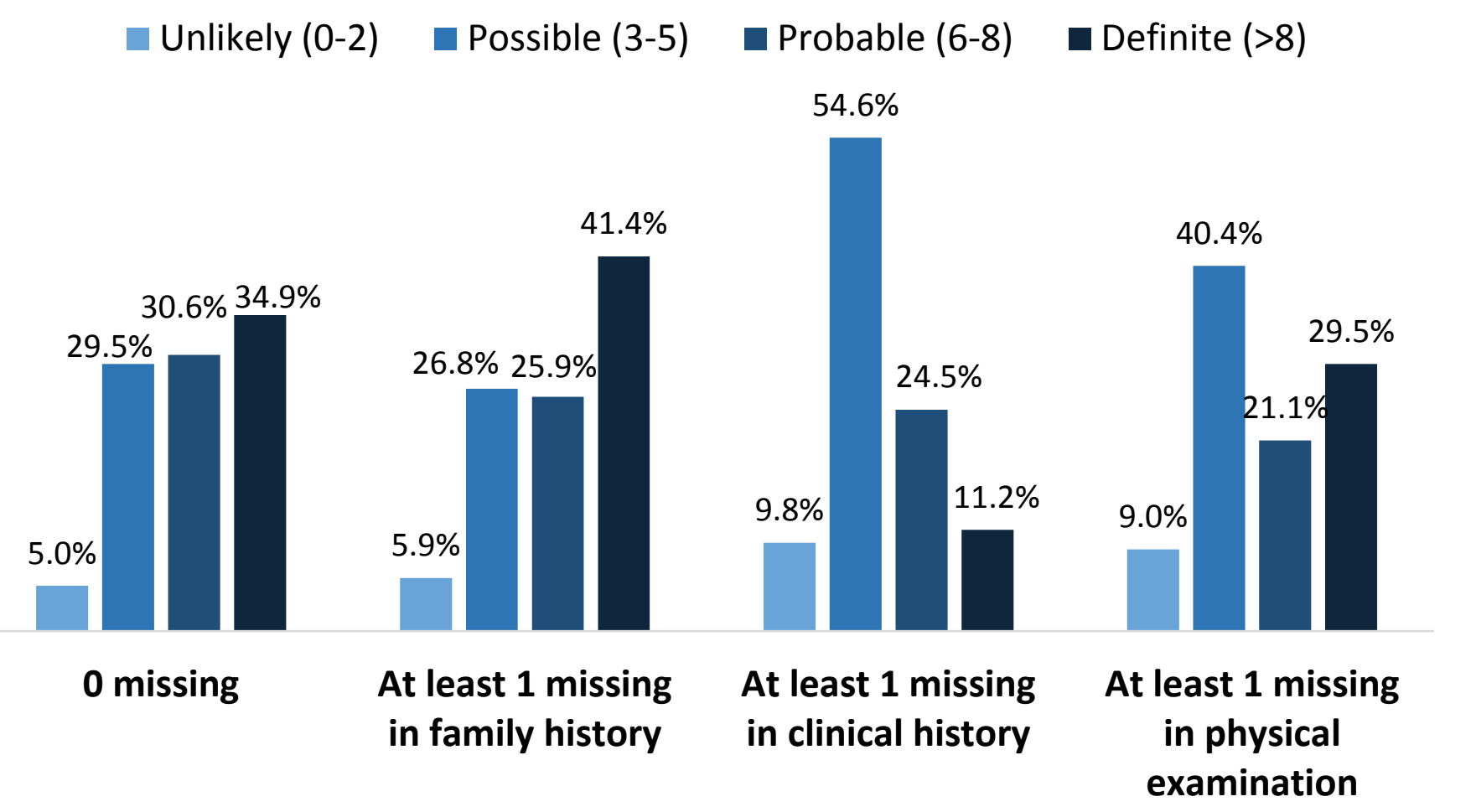

\section{AIM and METHODS}

To test the performance of the DLCN score based on completeness of required data, an analysis was carried out in all mutation-positive patients (as established by genetic test performed by different laboratories) enrolled in the LIPIGEN study, aged 18 years or more, who underwent clinical evaluation and had information on pre-treatment LDL-cholesterol (LDL-C) levels available. The DLCN performance was evaluated as a function of the number and type of missing criteria. In addition, a stepwise logistic regression analysis (odds ratios [OR] and $95 \% \mathrm{Cl}$ ) was carried out in order to identify which factors among DLCN criteria and other additional covariates (i.e. non-HDL-C, Lp(a), LDL-C $>180 \mathrm{mg} / \mathrm{dL}$ since age $<18$ years) had a greater impact in predicting the probability of having monogenic $\mathrm{FH}$.

As the pre-treatment LDL-C levels were not available for many FH subjects, we evaluated whether the use of estimated pre-treatment LDL-C based on statin type and dose might affect the DLCN score. Overall, 39.6\% of subjects without known pre-treatment LDL-C values had estimated LDL-C levels >325 $\mathrm{mg} / \mathrm{dL}$, leading to an overestimation of patients classified as probable/definite $\mathrm{FH}$.

\begin{tabular}{|lcccc|}
\hline LDL-C levels & $\begin{array}{c}\text { FH population } \\
\text { (N=1.377) }\end{array}$ & $\begin{array}{c}\text { Not on statin } \\
\text { (768) }\end{array}$ & $\begin{array}{c}\text { On treatment, } \\
\text { with known } \\
\text { pre-treatment } \\
\text { LDL-C levels (397) }\end{array}$ & $\begin{array}{c}\text { On treatment, } \\
\text { with estimated } \\
\text { pre-treatment } \\
\text { LDL-C levels (212) }\end{array}$ \\
\hline$<155 \mathrm{mg} / \mathrm{dL}$ & $2.47 \%$ & $2.60 \%$ & $1.26 \%$ & $4.25 \%$ \\
$155-190 \mathrm{mg} / \mathrm{dL}$ & $6.46 \%$ & $7.42 \%$ & $6.30 \%$ & $3.30 \%$ \\
$191-250 \mathrm{mg} / \mathrm{dL}$ & $28.40 \%$ & $28.91 \%$ & $31.74 \%$ & $20.28 \%$ \\
$251-325 \mathrm{mg} / \mathrm{dL}$ & $36.75 \%$ & $39.06 \%$ & $34.51 \%$ & $32.55 \%$ \\
$>325 \mathrm{mg} / \mathrm{dL}$ & $25.93 \%$ & $22.01 \%$ & $26.20 \%$ & $39.62 \%$ \\
$\mathrm{DLCN}$ score $>\mathbf{8}$ & $\mathbf{3 7 . 9 1 \%}$ & $\mathbf{3 3 . 4 6 \%}$ & $\mathbf{3 7 . 5 3 \%}$ & $\mathbf{5 4 . 7 2 \%}$ \\
\hline
\end{tabular}

For this analysis, 1650 adults with a clinical $\mathrm{FH}$ diagnosis $(78.2 \%$ with genetically-confirmed $\mathrm{FH}$ ) were enrolled. Among the 9 items evaluated for the DLCN score calculation, the presence of tendon xanthoma and very high LDL-C levels, in the patient and/or in first degree relatives, showed the strongest association with the probability of having monogenic $\mathrm{FH}$. Regarding the additional factors, the only one included in the final model was the detection of LDL-C>180 $\mathrm{mg} / \mathrm{dL}$ before 18 years old (OR 1.83 [1.26-2.66]). This factor could be considered together with DLCN criteria for the clinical diagnosis of $\mathrm{FH}$

\begin{tabular}{|c|c|c|c|}
\hline & OR & \multicolumn{2}{|c|}{$95 \% \mathrm{Cl}$} \\
\hline Tendon xanthoma & 2.47 & 1.41 & 4.32 \\
\hline Premature $\mathrm{CHD}$ & 1.24 & 0.79 & 1.94 \\
\hline LDL-C $>180 \mathrm{mg} / \mathrm{dL}$ since age $<18$ years & 1.83 & 1.26 & 2.66 \\
\hline $\begin{array}{l}\text { First-degree relative with known LDL-C }>95 \text { th } \\
\text { percentile by age and gender for country }\end{array}$ & 2.33 & 1.49 & 3.64 \\
\hline $\begin{array}{l}\text { First-degree relative with tendon xanthoma } \\
\text { and/or corneal arcus }\end{array}$ & 5.51 & 2.28 & 13.31 \\
\hline $\begin{array}{l}\text { Child(ren) }<18 \text { years with } L D L-C>95 \text { th percentile } \\
\text { by age and gender for country }\end{array}$ & 1.82 & 1.21 & 2.74 \\
\hline $155 \leq \mathrm{LDL}-\mathrm{C} \leq 190 \mathrm{mg} / \mathrm{dL}$ & 1.24 & 0.62 & 2.48 \\
\hline $191 \leq \mathrm{LDL}-\mathrm{C} \leq 250 \mathrm{mg} / \mathrm{dL}$ & 1.39 & 0.75 & 2.58 \\
\hline $251 \leq \mathrm{LDL}-\mathrm{C} \leq 325 \mathrm{mg} / \mathrm{dL}$ & 3.84 & 2.03 & 7.25 \\
\hline $\mathrm{LDL}-\mathrm{C}>325 \mathrm{mg} / \mathrm{dL}$ & 15.5 & 7.12 & 33.75 \\
\hline
\end{tabular}

\section{CONCLUSIONS}

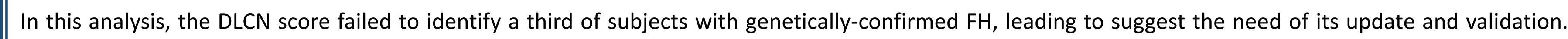

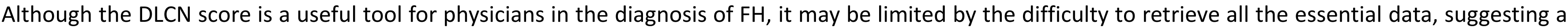
crucial role of the clinical judgement in the identification of $\mathrm{FH}$ subjects. 